\title{
Experimental validation of CFD simulations of bioaerosol movement in a mechanically ventilated airspace
}

\author{
Amy La and Qiang Zhang \\ Department of Biosystems Engineering, University of Manitoba, Winnipeg, MB R3T 5V6, Canada \\ Corresponding Author: Qiang Zhang (Qiang.Zhang@umanitoba.ca)
}

\section{ABSTRACT}

A CFD (computational fluid dynamics) model was developed to simulate the movement of bioaerosols in mechanically-ventilated chambers and the results were validated with experiments. Liquid aerosols containing Porcine Reproductive and Respiratory Syndrome Virus (PRRSV) were artificially generated in the chambers. Bioaerosol concentration was monitored with an optical particle counter until steady-state conditions were achieved (aerosols containing viruses are referred to as bioaerosols in this paper). Four treatments with two ventilation rates and two bioaerosol generation rates were tested. The standard $\mathrm{k}-\varepsilon$ turbulence model and a discrete phase model with unsteady tracking was used in an ANSYS Fluent CFD model to simulate the airflow and bioaerosol movement until steady-state was reached. A mesh refinement test was performed to select an optimal mesh size for simulations. The CFD simulations showed good agreement with the measured bioaerosol concentrations at steadystate with differences of $2 \%$ to $8 \%$, normalized mean square error of 0.01 to 0.19 , and fractional bias of 0.02 to 0.08 . Simulations and validation during the transient phase could not be verified because of limited measurement locations.

\section{KEYWORDS}

bioaerosol, computational fluid dynamics (CFD), ventilated airspace, airflow pattern.

\section{RÉSUMÉ}

Un modèle MFN [CFD] (mécanique des fluides numérique) a été développé pour simuler le mouvement de bioaérosols dans des salles ventilées mécaniquement et les résultats ont été validés par des essais. Des bioaérosols liquides contenant le virus du syndrome reproducteur et respiratoire porcin (SRRP) [PRRSV] ont été introduits artificiellement dans les salles. La concentration des bioaérosols a été mesurée avec un compteur optique de particules jusqu'à ce que des conditions en régime permanent soient atteintes (les aérosols contenant les virus sont appelés bioaérosols dans cette publication). Quatre traitements (deux taux de ventilation et deux taux d'introduction) ont été testés. Le modèle standard de turbulence $\mathrm{k}-\varepsilon$ et un modèle de phase discrète avec suivi non permanent ont été utilisés dans un modèle MFN ANSYS Fluent pour simuler l'écoulement de l'air et le mouvement des bioaérosols jusqu'à ce que l'équilibre soit atteint. Un test de raffinement du maillage a été réalisé pour obtenir un maillage optimal pour les simulations. Les simulations MFN ont donné des résultats similaires aux concentrations de bioaérosol mesurées en régime permanent avec des différences allant de 2 à $8 \%$, une erreur type normalisée de 0,01 à 0,19 et une erreur fractionnelle de 0,02 à 0,08 . Les simulations et la validation durant la phase transitoire n'ont pu être vérifiées en raison du nombre limité de points de mesure.

\section{CITATION}

La, A., and Q. Zhang. 2019. Experimental validation of CFD simulations of bioaerosol movement in a mechanically ventilated airspace. Canadian Biosystems Engineering/Le génie des biosystèmes au Canada 61: 5.01-5.14.

https://doi.org/10.7451/CBE.2019.61.5.01 


\section{INTRODUCTION}

Aerosols are small liquid or solid particles that are indefinitely suspended in the air. Aerosols containing viruses are commonly referred to as bioaerosols, which act as a carrier for many human and animal diseases, such as Avian Influenza. In the livestock industry, aerosol transmission of infectious pathogens from infected animal facilities over long distances to susceptible facilities is a problem that occurs despite conventional biosecurity measures.

Aerosol transmission of avian influenza virus (AIV) was previously demonstrated over short distances (Tsukamoto et al. 2007; Yao et al. 2011; Spekreijse et al. 2011, 2013) and using artificially-generated aerosols (Guan et al. 2013, 2015). Aerosol transmission of porcine reproductive and respiratory syndrome virus (PRRSV) has also been experimentally demonstrated over short distances (Kristensen et al. 2004; Torremorrell et al. 1997; Brockmeier and Lager 2002; Cho et al. 2007; Pitkin et al. 2009; Dee et al. 2010). Many researchers have demonstrated aerosol transmission of foot-and-mouth disease virus (FMDV) in experiments, in which animals became infected upon inhaling airborne virus generated by infected animals; animals that became infected upon aerosol exposure to FMDV include sheep (Gibson and Donaldson 1986), cattle (Donaldson et al. 1987; Colenutt et al. 2016), and pigs (Alexandersen et al. 2002). Evidences of longdistance transport of AIV and PRRSV have also been found in literature. Genes associated with the H5 subtype of AIV were detected in air samples collected during Asian dust storms (Chen et al. 2010). Additionally, infectious PRRSV was collected $4.7 \mathrm{~km}$ (Dee et al. 2009) and $9.1 \mathrm{~km}$ (Otake et al. 2010) downwind of an infected pig facility. While research has shown that aerosol transmission is a potential pathway for infectious pathogens to spread from facility to facility, our understanding of the mechanisms behind aerosol transmission is still limited. Based on an extensive literature review, Zhao et al. (2014) concluded that transmission of pathogens between animal operations through the airborne route remains largely unclear. Researchers have attempted to link pathogen transmission to prevalent wind directions as an epidemiological proof of airborne transmission, but this has not been consistently successful (Gloster et al. 2003; Mikkelsen et al. 2003).

Computational fluid dynamics (CFD) has provided a powerful tool for investigating aerosol behavior in the moving air. This method was used to determine the exposure of patients and visiting students to airborne severe acute respiratory coronavirus (SARS-CoV) within a threebay hospital ward, based on their distance from the index patient. The CFD simulation showed that imbalanced airflow within the ward led to patients and students that were staying or visiting the same bay as the index patient, respectively, to be exposed to higher concentrations of SARS-CoV than patients or visitors in adjacent and distant bays (Li et al. 2004; Wong et al. 2004; Yu et al. 2005). In a similar study by the same research group, a CFD simulation showed that the airflow pattern generated by an air purifier transported airborne influenza A virus from the index patient to an adjacent bay, likely leading to infection of patients in this bay (Wong et al. 2010). In another study, a CFD simulation predicted that a north-easterly wind blew SARS-CoV bioaerosols from one building to three other buildings in an apartment complex that experienced an outbreak of SARS-CoV (Yu et al. 2004). Seo et al. (2014) utilized CFD to determine if aerosol transmission was the cause of poultry facilities becoming infected with AIV during a 2008 outbreak in Korea; the study utilized both topographical and meteorological data in 960 simulations. The data was incorporated into a network model to distinguish between other possible modes of transmission. The study concluded that it was possible that two out of 13 facilities were infected due to aerosol transmission of AIV, while 10 out of 13 were likely infected due to fomite transfer (Lee et al. 2014).

A challenge of using CFD for simulating aerosol transmission of diseases is model validation. In most studies reported in the literature, model validation is performed indirectly by correlating the model predictions to observed disease events, instead of directly comparing predicted and measured aerosol concentrations. This is because measuring aerosol concentration in the air is difficult during outbreaks. In La (2015), controlled laboratory experiments were performed, in which bioaerosols of PRRSV were generated into two connected chambers. The purpose of the current study was to: (1) demonstrate the adequacy of CFD for simulating aerosol transmission by using the parameters measured in La (2015) to simulate bioaerosol movement in a mechanically-ventilated airspace (chambers), and (2) validate the CFD simulation by directly comparing the results to the measured bioaerosol concentrations in $\mathrm{La}$ (2015). Specifically, a CFD model was utilized to simulate the movement and distribution of bioaerosols containing PRRSV within two connected chambers.

\section{MATERIALS AND METHODS}

\section{Experimental Bioaerosol Chamber System}

The bioaerosol experiment system consisted of two identical chambers with dimensions of $0.99 \mathrm{~m}, 1.30 \mathrm{~m}, 1.07$ $\mathrm{m}$ in height, width, and depth, respectively (Fig. 1a). The two chambers were joined together with a $0.165-\mathrm{m}-$ diameter duct $0.603 \mathrm{~m}$ in length. The inlets of each chamber contained baffles that directed the airflow downwards to promote air circulation. A HEPA filter (model no. 01XS24Z12Z12, Camfil Farr, Winnipeg, MB) was installed prior to the inlet of the first chamber and after the outlet of the second chamber to remove any biological organisms from the air. A 0.127-m-diameter tee-wye (Y-shaped) fitting was installed between the first chamber and the HEPA filter; the branch of the fitting was used as a port to introduce bioaerosols into the chamber system.

The airflow (ventilation) within the chambers was generated by a fan (VortexVTX800, Atmosphere, Terrebonne, QC) and controlled using an IRIS damper 

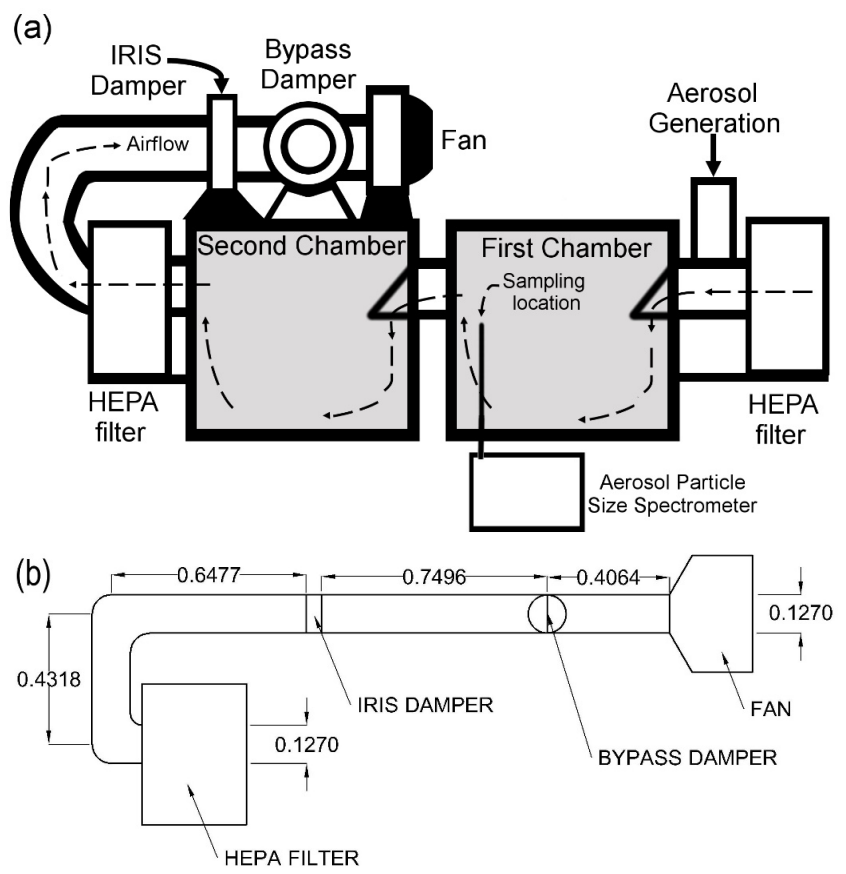

Fig. 1. (a) Sketch of the aerosol experiment system, (b) schematic diagram of the IRIS damper, digital manometer, bypass damper to control airflow rate in chambers (dimensions are in meters).

(IRIS-S-05, Continental Fan Manufacturing Inc., Mississauga, ON), a bypass damper, and digital manometer (475-00-FM, Dwyer, Michigan City, IN). The bypass damper was an air diffuser that was opened when a lower airflow rate was required in the chambers. These components were installed after the second HEPA filter and separated with 0.127 -m-diameter duct (Fig. 1b). The IRIS damper product specification guide specified that distances of $\geq 1 \mathrm{~d}$ and $\geq 2 \mathrm{~d}$ (where $\mathrm{d}$ is the diameter of the duct) for elbows and transitions, respectively, were required to obtain an airflow measurement accuracy of $\pm 7 \%$ (Continental Fans 2012). The distance that the IRIS damper was placed from the elbow and the bypass damper was $0.6477 \mathrm{~m}$ and 0.7496 $\mathrm{m}$, respectively, which met the requirements for accurate air flow rate measurement, as specified by the instrument supplier. It should be noted the requirements were different from the airflow measurement procedure outlined in ASHRAE (1987).

Bioaerosols were generated using a 6-jet Collison Nebulizer (CN25, BGI Inc., Waltham, MA) driven by filtered compressed air. The nebulizer was filled with 39 $\mathrm{ml}$ of PBS and $1 \mathrm{ml}$ of PRRSV produced from a live vaccine (Ingelvac PRRS ${ }^{\circledR}$ MLV, Boehringer Ingelheim, St. Joseph, $\mathrm{MO}$ ) with an initial virus concentration of $1 \times 10^{7} \mathrm{PFU} / \mathrm{ml}$. The final virus concentration in the aerosolized solution was $2.5 \times 10^{5} \mathrm{PFU} / \mathrm{ml}$. The nebulizer produced a bioaerosol generation rate of $14.8 \mathrm{ml} / \mathrm{h}$ and $34.0 \mathrm{ml} / \mathrm{h}$ when supplied with compressed air at 137.9 and $413.7 \mathrm{kPa}$, respectively. The bioaerosols were monitored with an Aerosol Particle Size Spectrometer (APSS; LAP 332, Topas GmbH,
Dresden, Germany) that was programmed to collect 10-s measurements for bioaerosol size and concentration repeatedly. Duration of measurements varied between 10 and $12.9 \mathrm{~s}$. The APSS was connected to $6.35-\mathrm{mm}$-ID Tygon tubing that collected air in the first chamber at a location that was $0.53 \mathrm{~m}$ from the outlet, at a height of $0.495 \mathrm{~m}$, and at a depth of $0.65 \mathrm{~m}$. A Tygon tube was connected to the outlet of the APSS to return air into the chamber and prevent virus from escaping. Since the APSS had a low total volumetric flow rate of $0.18 \mathrm{~m}^{3} / \mathrm{h}$ (Topas 2010) relative to the airflow rates used in this study, its airflow rate effect was considered negligible and was not modelled in this study.

Two airflow (ventilation) rates of $34.0 \mathrm{~m}^{3} / \mathrm{h}$ and 135.9 $\mathrm{m}^{3} / \mathrm{h}$ and two bioaerosol generation rates of $14.8 \mathrm{ml} / \mathrm{h}$ and $33.0 \mathrm{ml} / \mathrm{h}$ were tested. These airflow rates were chosen to match the Midwest Plan Service (MWPS) recommended ventilation rates of $34.0 \mathrm{~m}^{3} / \mathrm{h}$ and $135.9 \mathrm{~m}^{3} / \mathrm{h}$ per head of sow and litter in cold and mild weather, respectively (MWPS 1983). The MWPS recommended maximum ventilation rate could not be achieved due to the limited fan capacity of the test system. The combinations of airflow rates and bioaerosol generation rates provided four treatments (Treatment 1: $34.0 \mathrm{~m}^{3} / \mathrm{h}, 14.8 \mathrm{ml} / \mathrm{h}$; Treatment 2: $34.0 \mathrm{~m}^{3} / \mathrm{h}, 33.0 \mathrm{ml} / \mathrm{h}$; Treatment $3: 135.9 \mathrm{~m} / \mathrm{h}, 14.8 \mathrm{ml} / \mathrm{h}$; Treatment 4: $135.9 \mathrm{~m}^{3} / \mathrm{h}, 33.0 \mathrm{ml} / \mathrm{h}$ ), which generated four different steady-state bioaerosol concentrations in the chambers. Each treatment was performed three times. The time required to reach steady-state was calculated to be 16 minutes and 4 minutes for airflow rates of $34.0 \mathrm{~m}^{3} / \mathrm{h}$ and $135.9 \mathrm{~m}^{3} / \mathrm{h}$, respectively (La 2015).

\section{Smoke test}

A smoke test was performed for the airflow rate of 34.0 $\mathrm{m}^{3} / \mathrm{h}$ to qualitatively assess the movement of the airflow pattern, and specifically to confirm that: (a) the baffle installed to the inlet of the chamber was enough to direct airflow downward and allow for the bioaerosols to be welldistributed inside of the chamber, and (b) the airflow pattern demonstrated in the CFD simulation matched the airflow pattern observed in the smoke tests. Smoke cartridges (S103, REGIN HVAC Products Inc., Oxford, CT) were lit and placed in the angled branch of the tee-wye (Y-shaped) fitting. Airflow patterns were video-recorded through an observation window made of Plexiglass.

\section{CFD Simulation of Continuous Phase (air)}

Simulations were performed in ANSYS Workbench (18.1, ANSYS, Canonsburg, PA). Firstly, the geometry of the chambers was constructed in ANSYS DesignModeler. Some aspects of the chambers were simplified; most components before and after the inlet of the first chamber and outlet of the second chamber, respectively, were excluded from the geometry. In other words, the CFD simulation was focused on the chambers (Fig. 2). The mesh was designed in ANSYS Meshing. The mesh cell shape for the circular ducts, fittings, and baffles were unmodified from the default settings generated by ANSYS. The mesh cell shape of the chambers was modified from the default 

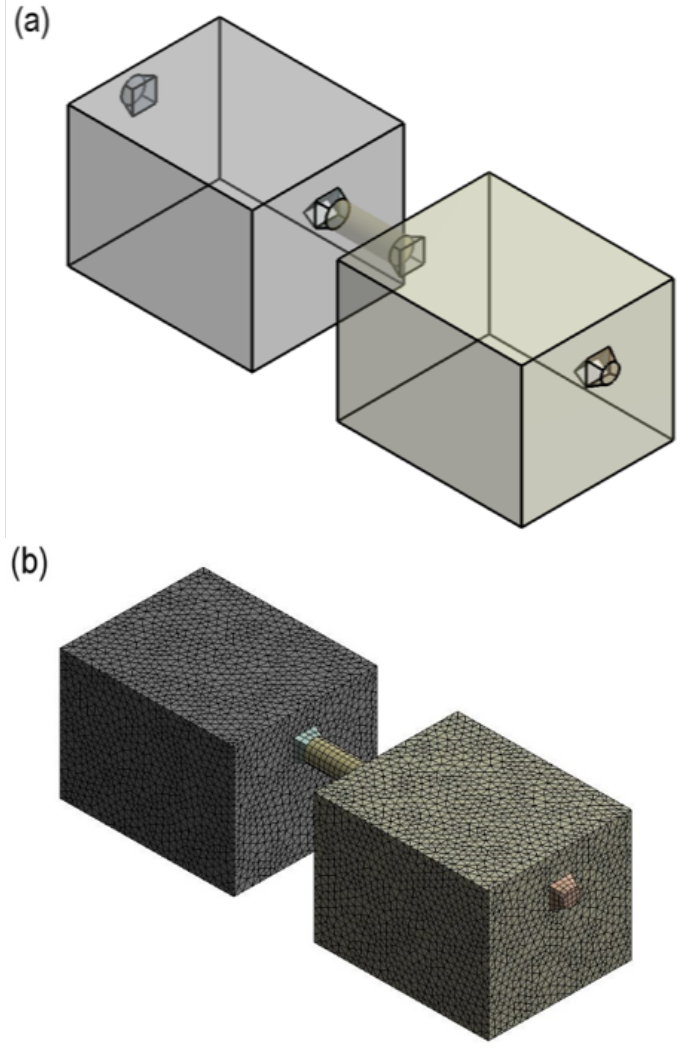

\section{Fig. 2. (a) Geometry of chambers and (b) Mesh with 0.05} $m$ size cells in chambers and baffles.

settings to tetrahedral cells (Fig. 2b), which increased the average mesh quality. Tetrahedral cells were chosen because they conformed better to the geometry of the chambers than hexahedral cells, especially at the entrance of the chambers where the baffles were located. The ANSYS User Guide also specifies that tetrahedral cells should be used in cases of relatively and extremely complex geometries (ANSYS 2013a). The circular faces on the circular-to-square fittings before and after the first and second chamber were set as the inlet and outlet, respectively. The remaining walls of the chambers, duct, baffles, and fittings were given a boundary condition of wall.

The boundary conditions at the inlet and outlet are indicated in Table 1 . The velocity at the inlet and mass flow rate at the outlet were calculated from the measured airflow rate according to eqns. 1 and 2, respectively.

$$
\begin{aligned}
& v=\frac{Q}{A} \\
& M_{\text {air }}=Q \times \rho_{\text {air }}
\end{aligned}
$$

where $v=$ velocity $(\mathrm{m} / \mathrm{s})$,

$M_{\text {air }}=$ mass flow rate of air exiting chambers $\left(\mathrm{kg} / \mathrm{m}^{3}\right)$

$Q=$ ventilation rate of the chambers $\left(\mathrm{m}^{3} / \mathrm{h}\right)$ (measured values were used in simulations).

$A=$ area of the inlet $\left(\mathrm{m}^{2}\right)$

$\rho_{\text {air }}=$ density of air $\left(1.19 \mathrm{~kg} / \mathrm{m}^{3}\right)$.

The pressure at the inlet was set to be equal to the initial resistance due to the HEPA filter at the utilized airflow rate, which was provided by the manufacturer (Camfil 2017). The pressure at the outlet was two times the pressure at the inlet due to the presence of a second filter at the outlet.

There are several options of turbulence models in ANSYS Fluent. Given that the emphasis of this study was to validate the adequacy of CFD in simulating the discrete phase (aerosols), the standard $k-\varepsilon$ model that was originally developed by Launder and Spalding (1972) was chosen to simulate the continuous phase (air) to avoid unnecessary convergence problems. The ANSYS Fluent User Guide describes the standard k- $\varepsilon$ model as robust and economical as well as able to provide good accuracy for many types of turbulent flow (ANSYS 2013a). The standard k- $\varepsilon$ model has been used to simulate the dispersion of dust and AIV in the environment (Seo et al. 2010, 2014).

The pressure-velocity coupling scheme utilized was the SIMPLE-C Scheme. Momentum, turbulent kinetic energy, and rate of turbulent dissipation were solved using the Second Order Upwind scheme. The Green-Gauss Node Based Scheme was used to solve for gradients for the Upwind scheme.

\section{Discrete Phase Modeling of Bioaerosols}

Discrete phase modelling (DPM) was performed within ANSYS Fluent to simulate bioaerosol movement. It should be noted that the simulations were conducted to match the experimental conditions. Visual inspection of the chambers during experiments revealed that some bioaerosols generated by the nebulizer condensed along the tee-wye fitting before reaching the first chamber. Therefore, instead of using the bioaerosol generation rate specified for the nebulizer, the bioaerosol generation rates by the nebulizer were estimated as follows, based on the bioaerosol concentrations measured by the APSS during the experiments (La 2015).

Table 1. Boundary conditions of CFD simulation.

\begin{tabular}{cllccc}
\hline \multirow{2}{*}{ Treatment } & \multicolumn{1}{c}{$\begin{array}{c}\text { Boundary } \\
\text { Condition }\end{array}$} & \multicolumn{1}{c}{ Type } & $\begin{array}{c}\text { Mass flow rate } \\
\left(\mathrm{kg} \mathrm{s}^{-1}\right)\end{array}$ & $\begin{array}{c}\text { Velocity } \\
\left(\mathrm{m} \mathrm{s}^{-1}\right)\end{array}$ & $\begin{array}{c}\text { Pressure } \\
(\mathrm{Pa})\end{array}$ \\
\hline \multirow{2}{*}{1 and 2} & Inlet & Velocity-inlet & N/A & 0.75 & -4.9768 \\
& Outlet & Pressure-outlet & 0.01124 & N/A & -9.9536 \\
\multirow{2}{*}{3 and 4} & Inlet & Velocity-inlet & N/A & 2.98 & -19.907 \\
& Outlet & Pressure-outlet & 0.04492 & N/A & -39.814 \\
\hline
\end{tabular}


Table 2. DPM parameters for particle injection in CFD simulation.

\begin{aligned} & \hline Parameter Value \\ & \hline Type of injection Surface injection (from inlet) \\ & Particle Type Inert \\ & Material Water-liquid \\ & Density $998.2 \mathrm{~kg} \mathrm{~m}^{-3} \\ &$ Drag-Law Stokes-Cunningham \\ & Stochastic tracking Discrete walk model \\ & Time constant 0.15 \\ & \hline\end{aligned}

$M_{\text {aerosol }}=\frac{C_{\text {measured }} \times Q}{10^{6} \times 3600}$

where $M_{\text {aerosol }}=$ Modified bioaerosol generation rate (bioaerosol mass flow rate) $(\mathrm{kg} / \mathrm{s})$,

$C_{\text {measured }}=$ Bioaerosol concentration measured in chamber experiments $\left(\mathrm{mg} / \mathrm{m}^{3}\right)$.

The velocity at which bioaerosols were injected into the chambers was assumed to be equal to the velocity of the continuous (air) phase at the entrance to the chamber. To simplify the simulation and reduce computational expenses, a uniform aerosol diameter was assumed in the CFD simulations. Bioaerosols usually have a size distribution that resembles a log-normal distribution (Cambra-López et al. 2010). Aerosol size variations could affect the simulation results, as aerosols of varied sizes behave differently in airflow. However, the size of droplet nuclei that are responsible for airborne disease transmission is normally in a narrow range. For example, Duguid (1946) reported that $97 \%$ of repository droplet nuclei were in a range of 0.5 to $12.0 \mu \mathrm{m}$. Yang et al. (2007) reported that $82 \%$ of droplet nuclei from coughing were in a narrow range of 0.74 to 2.12 $\mu \mathrm{m}$. The size of the bioaerosols measured in this experimental study were in a range of 0.24 to $12.46 \mu \mathrm{m}$ (as measured by the APSS). Therefore, the mass geometric mean diameters ( 1.15 to $1.53 \mu \mathrm{m})$ measured in the chamber experiment for each treatment were used as the diameters of the bioaerosols in the CFD simulations (Table 3) (La 2015). As discussed in the results, there was only a small relative difference in the steady-state bioaerosol concentrations between measured and simulated values ( $2 \%$ to $8 \%$ ); therefore, the assumption of a single uniform bioaerosol size did not drastically affect the simulation results of this study.
The general bioaerosol parameters used to perform discrete phase modelling are summarized in Tables 2 and 3. The density of the bioaerosols was assumed to be that of water at $20^{\circ} \mathrm{C}$. The bioaerosols were specified to be inert, indicating that the bioaerosols would not be affected by temperature and phase change. This assumption was made as there were no reactants in the air that would cause the bioaerosols to change in size or disappear from the chamber air after the bioaerosols had reached a stable condition (i.e., no further evaporation induced shrinkage in bioaerosol size).

To determine which drag law to use in the simulation, the Stokes settling velocity and Reynolds number of the bioaerosols were calculated (eqn. 4 and 5, respectively). The Reynolds numbers of the bioaerosols were $6.7 \times 10^{-6}$, $5.4 \times 10^{-6}, 6.5 \times 10^{-6}$, and $2.85 \times 10^{-6}$ for treatments $1,2,3$, and 4 , respectively. Since the Reynolds numbers were less than $10^{-4}$, the Stokes-Cunningham drag law was used to compute the drag force acting on the bioaerosols (De Nevers 2010), with the Cunningham correction factors, which were calculated as per the Fluent Theory Guide (ANSYS 2013b; eqn. 6). The value of molecular mean free path that was utilized in eqn. 6 was measured at ambient pressure, a temperature of $298.15 \mathrm{~K}$, and a relative humidity of $0 \%$ (Jennings 1988).

$$
\begin{aligned}
& V_{t}=\frac{g d_{p}^{2}\left(\rho_{p}-\rho_{f}\right)}{18 \mu} \\
& R_{p}=\frac{d_{p} V_{t} \rho_{f}}{\mu} \\
& C_{C}=1+\frac{2 \lambda}{d_{p}}\left(1.257+0.4 \exp \left(\frac{-1.1 d_{p}}{2 \lambda}\right)\right)
\end{aligned}
$$

where $V_{t}=$ Stokes settling velocity $\left(\mathrm{m} / \mathrm{s}^{1}\right)$, $R_{p}=$ Reynolds number of the bioaerosol,

$g=$ gravitational constant $\left(\mathrm{m} / \mathrm{s}^{2}\right)$,

$\rho_{p}=$ density of bioaerosol $\left(\mathrm{kg} / \mathrm{m}^{3}\right)$,

$\rho_{f}=$ density of air $\left(\mathrm{kg} / \mathrm{m}^{3}\right)$,

$\mu=$ dynamic viscosity of air $\left(1.845 \times 10^{-5} \mathrm{~kg} \mathrm{~m}^{-1} \mathrm{~s}^{-1}\right)$,

$C_{C}=$ Cunningham correction factor,

$\lambda=$ molecular mean free path $\left(6.691 \times 10^{-8} \mathrm{~m}\right)$,

$d_{p}=$ mean diameter $(\mathrm{m})$.

Table 3. DPM injection parameters for treatments 1 to 4 .

\begin{tabular}{cccccccc}
\hline Treatment & $\begin{array}{c}\mathrm{M}_{\text {aerosol }} \\
(\mathrm{kg} / \mathrm{s})\end{array}$ & $\begin{array}{c}\mathrm{v} \\
(\mathrm{m} / \mathrm{s})\end{array}$ & $\begin{array}{c}\mathrm{d}_{\mathrm{p}} \\
(\mu \mathrm{m})\end{array}$ & $\mathrm{C}_{\mathrm{C}}$ & $\mathrm{T}(\mathrm{s})$ & $\mathrm{t}(\mathrm{s})$ & $\mathrm{N}$ \\
\hline 1 & $1.28 \times 10^{-8}$ & 2.98 & 1.508 & 1.11 & 300.608 & 0.05333 & 19200 \\
2 & $1.77 \times 10^{-8}$ & 2.98 & 1.147 & 1.15 & 300.608 & 0.05333 & 19200 \\
3 & $5.86 \times 10^{-9}$ & 0.75 & 1.526 & 1.11 & 1023.94 & 0.01342 & 22400 \\
4 & $1.39 \times 10^{-8}$ & 0.75 & 1.416 & 1.12 & 1023.94 & 0.01342 & 22400 \\
\hline
\end{tabular}

$\mathrm{M}_{\text {aerosol }}$ - Aerosol mass flow rate, $\mathrm{v}-$ velocity of aerosols entering the chamber, $\mathrm{d}_{\mathrm{p}}-$ diameter of aerosols, $\mathrm{C}_{\mathrm{C}}-\mathrm{Cunningham} \mathrm{Correction}$ Factor, $\mathrm{T}$ - total simulation time, $\mathrm{t}$ - size of time step, $\mathrm{N}$ - total number of time steps. 
Table 4. Mesh characteristics, number of nodes, combined volume of cells, and coordinate range of nodes used to determine mean aerosol concentration in mesh refinement tests.

\begin{tabular}{lcccccc}
\hline \multicolumn{2}{c}{ Mesh Characteristics } & \multicolumn{3}{c}{ Nodes surrounding measurement coordinate } \\
$\begin{array}{l}\text { Cell Size } \\
(\mathrm{m})\end{array}$ & \# cells & \# nodes & $\begin{array}{c}\text { Combined } \\
\text { volume of cells } \\
\left(\mathrm{m}^{3}\right)\end{array}$ & $\mathrm{X}$ & $\mathrm{Y}$ & $\mathrm{Z}$ \\
\hline 0.0425 & 506720 & 54 & 0.001777 & $0.428-0.529$ & $0.434-0.535$ & $0.477-0.578$ \\
0.045 & 415563 & 45 & 0.001758 & $0.415-0.522$ & $0.452-0.559$ & $0.488-0.573$ \\
$0.05^{\mathrm{B}}$ & 306117 & 35 & 0.001876 & $0.412-0.507$ & $0.447-0.542$ & $0.485-0.58$ \\
0.05625 & 218736 & 30 & 0.002289 & $0.410-0.516$ & $0.442-0.548$ & $0.482-0.589$ \\
0.075 & 92629 & 16 & 0.002894 & $0.401-0.507$ & $0.459-0.566$ & $0.473-0.58$ \\
\hline
\end{tabular}

A body sizing performed on mesh of the chambers and baffles

B $0.05 \mathrm{~m}$ mesh was chosen for the remaining simulations

Interaction of bioaerosols with the continuous phase (air) was activated to allow for unsteady tracking and injection of bioaerosols during the DPM simulation. The simulation time was subdivided into smaller time increments (steps). Parcels containing bioaerosols were generated into the chamber at the beginning of each time step and the movement of the generated bioaerosols were tracked during each time step. The simulation time chosen for the DPM was $60 \mathrm{~s}$ plus the time required for the bioaerosol concentration to reach steady-state within the chambers, as calculated in $\mathrm{La}$ (2015). The length of a time step and the total number of time steps were calculated as indicated by the ANSYS Fluent User's Manual (eqn. 7 and 8, respectively; ANSYS 2013a).

$$
\begin{aligned}
& t=\frac{x_{\min }}{v} \\
& N=\frac{T}{t}
\end{aligned}
$$

where, $t=$ length of time step (s),

$x_{\text {min }}=$ minimum mesh size $(\mathrm{m})$,

$v=$ velocity of airflow during treatment $(\mathrm{m} / \mathrm{s})$,

$N=$ total number of time steps for treatment,

$T=$ simulation time, or time to steady-state (s).

\section{Mesh Refinement Test}

The influence of mesh size on the simulation results was tested by performing the same simulation using five meshes of different cell sizes. Firstly, the minimum cell size was set to $0.04 \mathrm{~m}$ for each tested mesh. The cell size of the two chambers and baffles were altered, while the cell size of the ducts and fittings were not altered. Body sizing was performed on the chambers and baffles to sizes of 0.0425 $\mathrm{m}, 0.045 \mathrm{~m}, 0.05 \mathrm{~m}, 0.0565 \mathrm{~m}$, and $0.075 \mathrm{~m}$. The number of cells per mesh is shown in Table 4 .

Simulations of treatment 3 tests were then performed on each mesh. An airflow rate of $135.9 \mathrm{~m}^{3} / \mathrm{h}$ resulted in airflow that was more turbulent than an airflow rate of 34.0 $\mathrm{m}^{3} / \mathrm{h}$. Additionally, increasing the amount of particle generation in the CFD simulation increased the simulation time. Thus, treatment 3 was chosen to ensure that the mesh could accurately measure the airflow properties of the more turbulent airflow rate, while also decreasing the length of time required to run the multiple mesh refinement simulations.

The bioaerosol concentrations within the chambers were extracted at the final time step for each mesh. The bioaerosol concentrations measured in the experimental study were compared to the mean, standard deviation, and range of bioaerosol concentrations within the nodes surrounding the location where bioaerosol measurements were carried out. The bioaerosol concentration within the volume of cells surrounding the measurement point was calculated as per eqn. 9 .

$$
C_{\text {surround }}=\frac{\sum_{n_{\text {node }}}\left(C_{\text {node }} \times V_{\text {node }}\right)}{\sum_{n_{\text {node }}} V_{\text {node }}}
$$

where $C_{\text {surround }}=$ bioaerosol concentration in cells surrounding measurement point $\left(\mathrm{mg} / \mathrm{m}^{3}\right)$,

$n_{\text {node }}=$ number of nodes surrounding the measurement point,

$C_{\text {node }}=$ bioaerosol concentration at node $\left(\mathrm{mg} / \mathrm{m}^{3}\right)$,

$V_{\text {node }}=$ volume of cells adjacent to nodes $\left(\mathrm{m}^{3}\right)$.

\section{Data Analysis}

Bioaerosol concentration Results of the CFD simulation were collected from CFD-Post. For treatments 1 and 2, results were analyzed every 100 time steps, which was equivalent to every $10.667 \mathrm{~s}$. For treatments 3 and 4, the results were analyzed every 400 time steps, which was equivalent to every $10.736 \mathrm{~s}$. The coordinates of nodes, volume of cells, and bioaerosol concentration at nodes were exported to Excel Spreadsheets. Equation 9 was used to calculate the bioaerosol concentration in a zone consisting of nodes closest to where the experimental bioaerosol concentration measurements occurred. The simulated bioaerosol concentrations at steady-state were compared to the measured bioaerosol concentrations using: (a) the six simulated bioaerosol concentration values prior to steadystate being accomplished; (b) the six simulated bioaerosol concentration values after steady-state was accomplished.

At the final time step $(\mathrm{t}=1023.936 \mathrm{~s}$ for treatments 1 and 2 ; $\mathrm{t}=300.608 \mathrm{~s}$ for treatments 3 and 4 ), the velocity and 
bioaerosol concentration profiles at the centerline of flow were captured by creating a plane along the XY plane at $\mathrm{z}=0.535 \mathrm{~m}$ and creating a contour profile on this plane. The overall bioaerosol concentration within the first chamber was also calculated (Eqn. 10).

$$
C_{\text {chamber }}=\frac{\sum_{n_{\text {node, chamber }}}\left(C_{\text {node }} \times V_{\text {node }}\right)}{\sum_{n_{\text {node, chamber }}} V_{\text {node }}}
$$

where $C_{\text {chamber }}=$ bioaerosol concentration in the chamber $\left(\mathrm{mg} / \mathrm{m}^{3}\right)$,

$n_{\text {node, } \text { chamber }}=$ number of cells in a chamber.

Normalized mean square error and fractional bias ASTM specifies that indoor air quality models can be evaluated for their ability to calculate airborne pollutant concentration using the Normalized Mean Square Error (NMSE; ASTM 2008). ASTM standard D5157-97 specifies the equation and a threshold of 0.25 to indicate that the performance of the indoor air quality model is sufficient at predicting measured pollutants. Equation 11 was applied in this study. The NMSE was calculated for all measured bioaerosol concentrations. Because the APSS measurement durations varied from measurement to measurement, the time that bioaerosol concentration measurements occurred varied slightly between replicates. Additionally, the simulated bioaerosol concentrations occurred at slightly different times than the measured bioaerosol concentrations. To rectify the discrepancies in measurement time, the average time between replicates was compared to the CFD simulation time. Simulated bioaerosol concentrations were compared to measured bioaerosol concentrations with an average time between a range of the CFD simulation time $\pm 6.45 \mathrm{~s}$. A value of $6.45 \mathrm{~s}$ was chosen as it is 0.5 times the maximum measurement duration for the APSS (12.9 s). Additionally, the NMSE was calculated at steady-state for each of the measurements.

The fractional bias (FB) was also calculated by using equation 12, according to ASTM D5157-97 (ASTM 2008). The standard recommends a threshold of \pm 0.25 to evaluate the performance of the indoor air quality model. The FB was calculated during the span of the CFD simulation, comparing measured and simulated values at the time points specified for the NMSE. The FB was also calculated to compare steady-state measured and simulated bioaerosol concentrations.

$$
\begin{array}{r}
\text { NMSE }=\frac{\sum_{i=1}^{n}\left(C_{p}-C_{o i}\right) / n}{\left(C_{p}\right) \times\left(C_{\text {o, average }}\right)} \\
F B=2 \times \frac{\left(C_{p}-C_{o, \text { average }}\right)}{\left(C_{p}+C_{o, \text { average }}\right)}
\end{array}
$$

where NMSE $=$ normalized mean square error,

$\mathrm{FB}=$ fractional bias,

$C_{p}=$ simulated bioaerosol concentration $\left(\mathrm{mg} / \mathrm{m}^{3}\right)$,

$C_{o i}=$ measured bioaerosol concentrations at replicate $i$ of treatment test $\left(\mathrm{mg} / \mathrm{m}^{3}\right)$,

$C_{\mathrm{o} \text {, average }}=$ average measurement bioaerosol concentration $\left(\mathrm{mg} / \mathrm{m}^{3}\right)$,

$n=$ number of replicates per treatment.

\section{RESULTS AND DISCUSSION}

\section{Mesh Refinement Test}

The results of the mesh refinement tests are summarized in Table 5. The simulated bioaerosol concentrations calculated by eqn. 9 were identical to the mean simulated bioaerosol concentrations because the volumes of cells used to calculate the nodal bioaerosol concentrations did not differ much between tested meshes.

The mean simulated bioaerosol concentration was greater in the mesh size of $0.075 \mathrm{~m}$ than the other mesh sizes and there was also a greater variation in bioaerosol concentration between cells. The mean simulated bioaerosol concentration at this mesh size $\left(0.64 \mathrm{mg} / \mathrm{m}^{3}\right)$ was also much greater than the experimental bioaerosol concentration $\left(0.34 \mathrm{mg} / \mathrm{m}^{3}\right)$. Comparatively, utilizing mesh sizes of $0.04 \mathrm{~m}, 0.0425 \mathrm{~m}, 0.05 \mathrm{~m}$, and $0.05625 \mathrm{~m}$ resulted in bioaerosol concentrations that were closer to the mean bioaerosol concentration. A mesh size of $0.05 \mathrm{~m}$ was chosen to be used for subsequent simulations as there was not a large $(<3 \%)$ difference in mean bioaerosol concentration between mesh sizes of $0.05 \mathrm{~m}$ and $0.045 \mathrm{~m}$ as well as mesh sizes of $0.05 \mathrm{~m}$ and $0.0425 \mathrm{~m}$. Also, this mesh size would require less computational resources in future simulations. Decreasing the mesh size results in an increase in the number of elements in the mesh. Because ANSYS Fluent calculates the airflow properties and tracks the particle movement within each element, increasing the number of elements requires more computer resources and more time to complete a simulation.

\section{Model Validation}

Qualitative comparison of airflow pattern A qualitative comparison of the experimental and simulated airflow patterns in the first chamber was accomplished using a smoke test when the fan was operating at a ventilation rate of $34.0 \mathrm{~m}^{3} / \mathrm{h}$. Fig. 3 show the movement of smoke within the first chamber from 3 to $60 \mathrm{~s}$, while the movement of bioaerosols in the CFD simulation of treatment 1 from 10 to $64 \mathrm{~s}$ is shown in Fig. 4. Both the smoke images and simulations showed the air was directed downwards by the baffle. Additionally, the smoke did not initially enter the lower right corner of the chamber, which also occurred in the CFD simulation. In Fig. 3b-d, it can be noted that about $60 \mathrm{~s}$ was required for the smoke to fully distribute in the chamber. Similarly, about $60 \mathrm{~s}$ was required for the bioaerosols to distribute within the chamber in the CFD simulation (Fig. 4b-d). No further observations could be made after $60 \mathrm{~s}$ as the chamber was fully filled with thick smoke. 
Table 5. Mean, standard deviation, and range of simulated aerosol concentration in nodes surrounding measurement point in mesh refinement tests.

\begin{tabular}{lcccc}
\hline $\begin{array}{c}\text { Mesh size in } \\
\text { chambers } \\
(\mathrm{m})\end{array}$ & \multicolumn{5}{c}{$\begin{array}{c}\text { Aerosol concentration } \\
\left(\mathrm{mg} / \mathrm{m}^{3}\right)\end{array}$} \\
\hline & Mean & SD & Range & \% difference ${ }^{\mathrm{A}}$ \\
\cline { 2 - 5 } 0.0425 & 0.35 & 0.06 & $0.23-0.49$ & 2.8 \\
0.045 & 0.37 & 0.06 & $0.25-0.49$ & 2.8 \\
0.05 & 0.36 & 0.06 & $0.22-0.47$ & -- \\
0.5625 & 0.33 & 0.05 & $0.24-0.44$ & 8.3 \\
0.075 & 0.64 & 0.52 & $0.07-1.65$ & 77.8 \\
\hline
\end{tabular}

A compared to $0.05 \mathrm{~m}$ mesh

The velocity profile at the centerline of the chambers is shown in Fig. 5. Since the boundary conditions for the continuous phase were the same for treatments 1 and 2 , the velocity profiles for these two treatments were almost identical. A similar observation was made for the centerline velocity profiles of treatments 3 and 4 . The velocity profiles also indicated that the airflow was directed diagonally downwards towards the floor by the baffles before the air moved up towards the outlet of the first chamber. The movement of air downwards at the entrance of the first chambers indicated that the baffles were correctly modelled, in terms of the geometry and the boundary conditions, as this airflow pattern was also observed in the smoke test. A more detailed view of the velocity is shown in the velocity streamlines in the entire chamber system (Fig. 6). While the velocity streamlines of treatments 1 and 2 were not identical, the two streamlines had similar airflow patterns (only treatment 1 shown). A similar observation was made about the velocity streamlines of treatments 3 and 4 (only treatment 3 shown). Overall, the airflow moved in a clockwise direction in both the velocity streamlines, with no movement in the backwards direction.

Bioaerosol concentration The change of bioaerosol concentration at the measurement point with time during the experiment and the CFD simulation are shown in Fig. 7. The NMSE and FB values used to evaluate the performance of the CFD simulation at predicting the measured bioaerosol concentration are shown in Fig. 8. The dashed lines in Fig. 8a and 8b indicate that the NMSE was below the good performance indicator of 0.25 and that the simulated results were acceptable. Similarly, the FB values between the two dashed lines in Fig. 8c and 8d indicate that the simulated bioaerosol concentrations were not biased and were acceptable. According to the NMSE and FB values, the majority of simulated bioaerosol concentrations after $400 \mathrm{~s}$ were good predictors of the measured bioaerosol concentrations for treatments 1 and 2. Similarly, for treatments 3 and 4, the majority of simulated bioaerosol concentrations predicted after $120 \mathrm{~s}$ were good predictors of the measured bioaerosol concentrations. In other words, the
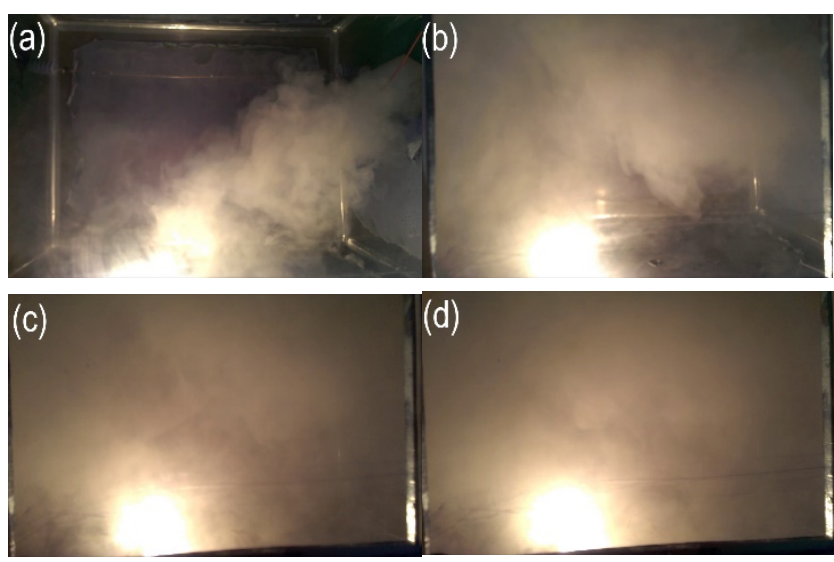

Fig. 3. Distribution of smoke (grey / white cloud) in chambers (black background) during smoke test at ventilation rate of $34.0 \mathrm{~m} 3 \mathrm{~h}-1$ at (a) $3 \mathrm{~s}$, (b) $30 \mathrm{~s}$, (c) $50 \mathrm{~s}$, and (d) $60 \mathrm{~s}$. White orb seen in pictures is a light source that was used to make smoke visible in video recording.

CFD simulations were adequate once the flow system reached steady-state, and the CFD simulations could be improved for the transient state of the simulation (i.e., before steady-state was reached). In Fig. 7, it is evident that there was some variation in bioaerosol concentration between experimental replicates during the transient phase. This variation increases the difficulty of satisfying the NMSE and FB criteria.

Overall, the steady-state concentrations generated by the CFD simulations compared well with the measured bioaerosol concentrations in all treatments. A comparison of the measured and simulated bioaerosol concentrations at the (a)

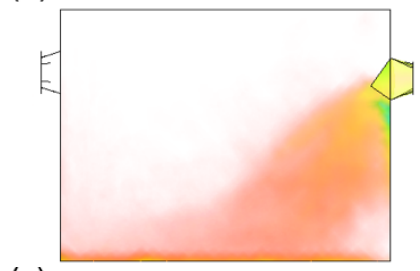

(c)

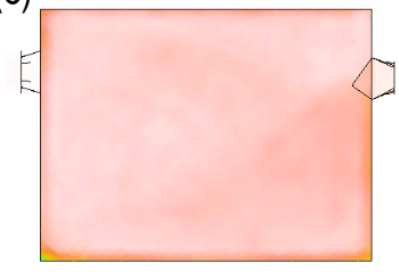

(d)
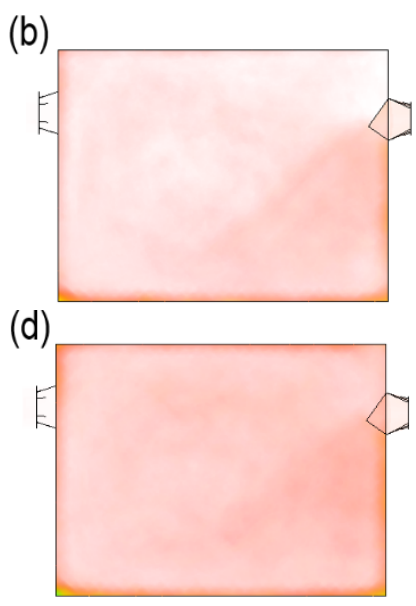

Fig. 4. Volume rendering of particle concentration in first chamber during treatment one at (a) $10.67 \mathrm{~s}$, (b) $32.01 \mathrm{~s}$, (c) $53.35 \mathrm{~s}$, (d) $64.02 \mathrm{~s}$ 

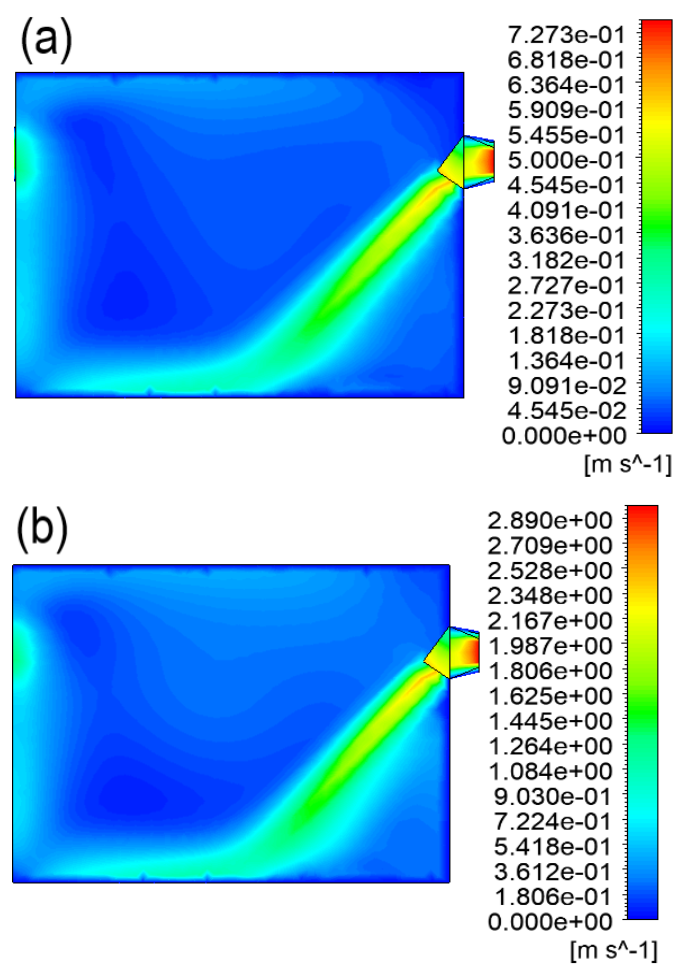

Fig. 5. Velocity profiles at centerline of flow for (a) treatments 1 and 2, (b) treatments 3 and 4.

measurement point and three evaluation techniques is presented in Table 6. The mean measured bioaerosol concentration was calculated from the results of three replicates per treatment. For each replicate, the average of six bioaerosol concentration measurements that occurred before steady-state was calculated; the three replicate average values were calculated to obtain the steady-state measured bioaerosol concentration per treatment. Additionally, there are two mean simulated bioaerosol concentrations per treatment. The first and second CFD (a)

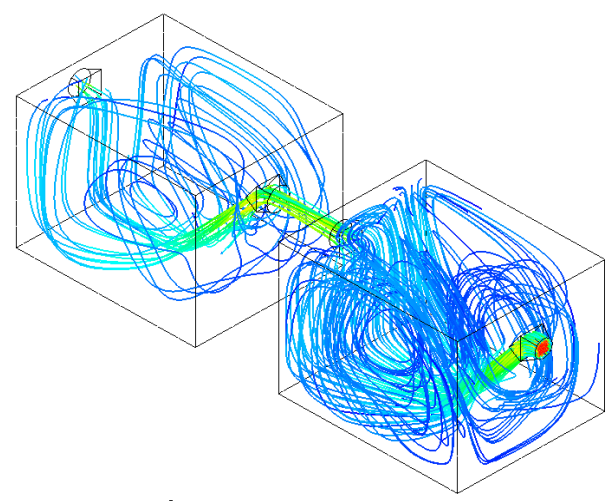

(b)
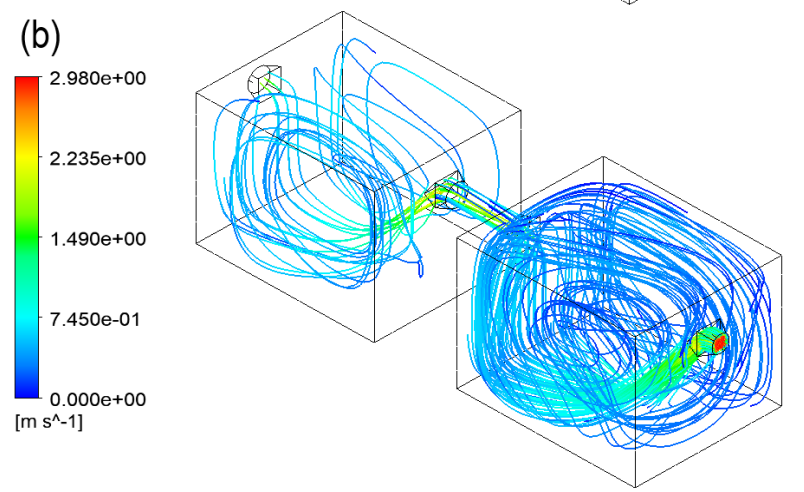

Fig. 6. Velocity streamlines of (a) treatment 1 and (b) treatment 3 simulations.

values are the averages of six data points before and after steady-state was reached, respectively. In terms of relative difference, the simulated bioaerosol concentrations compared well to the measured bioaerosol concentrations, with the lowest and highest differences occurring in treatment three and four $(2 \%)$ and treatment $1(8 \%)$, respectively. In terms of both NMSE and FB, the steadystate simulated bioaerosol concentrations for all treatments met the criteria provided by ASTM. The lowest and highest NMSE were 0.01 and 0.19 for treatments 1 and 3,

Table 6. Comparison of measured and simulated aerosol concentrations $\left(\mathrm{mg} / \mathrm{m}^{3}\right)$ at steady-state using Normalized Mean Square Error (NMSE), Fractional Bias (FB), and relative difference.

\begin{tabular}{|c|c|c|c|c|c|c|c|c|}
\hline \multirow[t]{2}{*}{ Treatment } & \multicolumn{2}{|c|}{1} & \multicolumn{2}{|c|}{2} & \multicolumn{2}{|c|}{3} & \multicolumn{2}{|c|}{4} \\
\hline & Mean & $\mathrm{SD}$ & Mean & SD & Mean & SD & Mean & $\mathrm{SD}$ \\
\hline Measured & 0.62 & 0.06 & 1.47 & 0.64 & 0.34 & 0.18 & 0.47 & 0.09 \\
\hline CFD (before $\mathrm{SS}^{\mathrm{A}}$ ) & 0.65 & 0.03 & 1.54 & 0.13 & 0.33 & 0.01 & 0.48 & 0.04 \\
\hline $\mathrm{CFD}\left(\right.$ after $\left.\mathrm{SS}^{\mathrm{B}}\right)$ & 0.67 & 0.03 & 1.54 & 0.17 & 0.35 & 0.01 & 0.49 & 0.04 \\
\hline $\mathrm{NMSE}^{\mathrm{C}}$ before SS & \multicolumn{2}{|c|}{0.01} & \multicolumn{2}{|c|}{0.10} & \multicolumn{2}{|c|}{0.19} & \multicolumn{2}{|c|}{0.02} \\
\hline NMSE after SS & \multicolumn{2}{|c|}{0.01} & \multicolumn{2}{|c|}{0.10} & \multicolumn{2}{|c|}{0.18} & \multicolumn{2}{|c|}{0.02} \\
\hline $\mathrm{FB}^{\mathrm{D}}$ before $\mathrm{SS}$ & \multicolumn{2}{|c|}{0.05} & \multicolumn{2}{|c|}{0.04} & \multicolumn{2}{|c|}{-0.04} & \multicolumn{2}{|c|}{0.02} \\
\hline FB after SS & \multicolumn{2}{|c|}{0.08} & \multicolumn{2}{|c|}{0.03} & \multicolumn{2}{|c|}{0.02} & \multicolumn{2}{|c|}{0.04} \\
\hline Difference before SS (\%) & \multicolumn{2}{|c|}{5} & \multicolumn{2}{|c|}{4} & \multicolumn{2}{|c|}{4} & \multicolumn{2}{|c|}{2} \\
\hline Difference after SS (\%) & \multicolumn{2}{|c|}{8} & \multicolumn{2}{|c|}{4} & \multicolumn{2}{|c|}{2} & \multicolumn{2}{|c|}{5} \\
\hline
\end{tabular}

\footnotetext{
${ }^{\mathrm{A}}$ before SS $=$ average of six measurements before steady-state reached (960 s for treatments 1 and 2; 240 s for treatments 3 and 4)

B after SS = average of six measurements after steady-state reached (approximately $960 \mathrm{~s}$ to $1024 \mathrm{~s}$ for treatments 1 and 2; approximately $240 \mathrm{~s}$ to $300 \mathrm{~s}$ for treatments 3 and 4 ).

${ }^{\mathrm{C}}$ NMSE less than 0.25 shows that the CFD simulation met ASTM criterion for predicting the measured aerosol concentrations.

D FB between -0.25 and 0.25 shows that the CFD simulation met the ASTM criterion for predicting the measured aerosol concentration.
} 

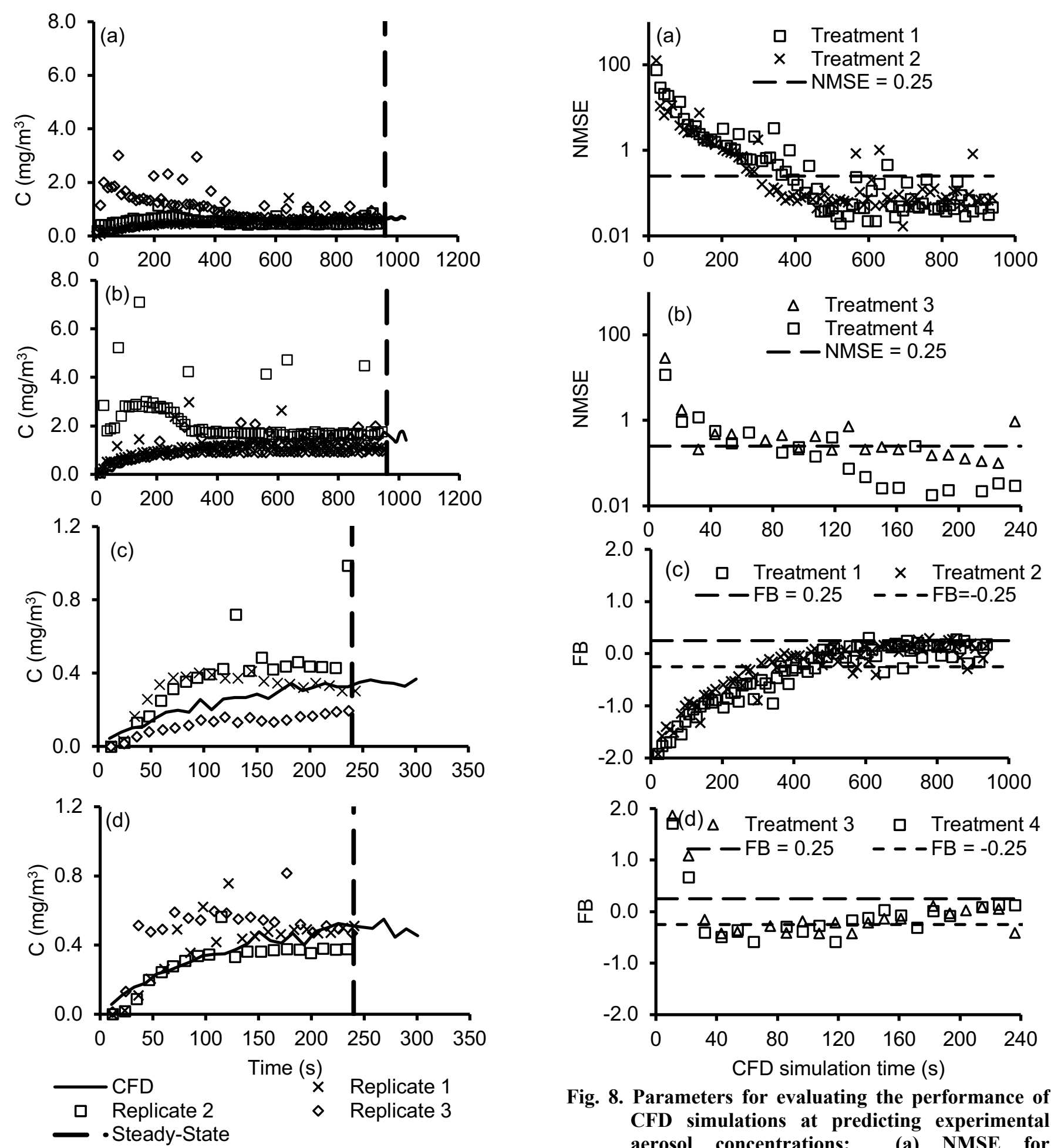

Fig. 8. Parameters for evaluating the performance of CFD simulations at predicting experimental aerosol concentrations: (a) NMSE for treatments 1 and 2, (b) NMSE for treatments 3 and 4, (c) FB for treatments 1 and 2, and (d) FB for treatments 3 and 4 . Values lower than the dashed line in (a) and (b), and the area between the dashed lines in (c) and (d) indicate the NMSE and FB values, respectively, that show that model is not biased and performed adequately according to ASTM standards. 
Table 7. Average and range of simulated aerosol concentrations $\left(\mathrm{mg} / \mathrm{m}^{3}\right)$ in the first chamber.

\begin{tabular}{ccc}
\hline Treatment & Average & Range \\
\hline 1 & 1.13 & $0.2-70.9$ \\
2 & 2.68 & $0.5-177.0$ \\
3 & 0.78 & $0.1-120.1$ \\
4 & 1.08 & $0.1-164.0$ \\
\hline
\end{tabular}

respectively, while the lowest and highest FB were 0.02 and 0.08 for treatments 3 and 4 , and 1, respectively.

The average and range of simulated bioaerosol concentrations in chamber 1 are shown in Table 7. The nonuniform distribution of bioaerosols was evident in the profiles of simulated bioaerosol concentration at the centerline of the chambers (Fig. 9). The distribution of bioaerosols for treatments 1 and 2 were similar, albeit the magnitudes of bioaerosol concentration were different. Similar patterns were also observed for treatments 3 and 4 . Higher concentrations of bioaerosols were visible at some locations, such as the left bottom edge of the chamber. This was probably because these areas had stagnant airflow, resulting in accumulation of bioaerosols. The stagnant zone is evident in Fig. 5, where the lighter colours in the corners indicate lower airflow velocity. In contrast, areas with higher velocity airflow had lower bioaerosol concentration. This can be confirmed by comparing the velocity profile (Fig. 5) and bioaerosol concentration profiles (Fig. 9). While the CFD simulations predicted the patterns of bioaerosol distribution in the chamber, the predictions could not be validated by the experimental data in this study because bioaerosols were measured at only one location. More measurements at different locations in the chamber would be required to fully validate the spatial distribution simulated by the CFD model.

\section{Relevance of study to current knowledge}

Observed outbreak events are often used to develop or validate models that predict the contribution of aerosol transmission to disease outbreak. For animal disease outbreaks, models have been developed to predict the movement and dispersion of aerosols from infected animal houses. The results were compared to observed outbreak events to determine what proportion of the outbreaks were due to aerosol transmission (Ssematimba et al. 2012; Seo et al. 2014; Lee et al. 2014). For human infectious disease outbreaks, CFD simulations were used as a tool to provide evidence of aerosol transmission and explain why observed infection events occurred ( $\mathrm{Li}$ et al. 2004; Yu et al. 2004; Wong et al. 2010). CFD simulations can potentially be used to quantitatively predict outbreaks of airborne human and animal diseases. Performing air sampling or aerosol concentration measurements to validate CFD simulations can provide confidence in the CFD simulation results. While airflow measurements were performed in the studies of Li et al. (2004) and Wong et al. (2010), no air sampling or aerosol concentration measurements occurred in the CFD simulation studies discussed.

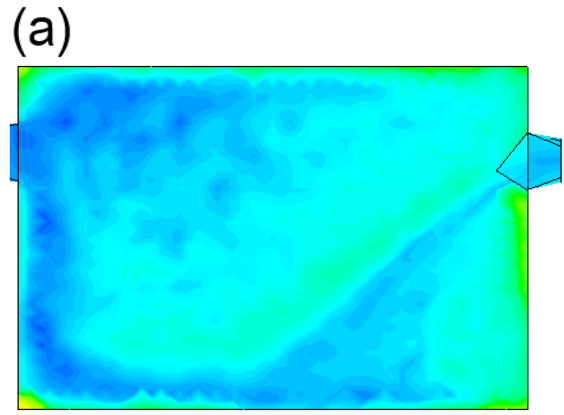

$1.435 \mathrm{e}-05$

$9.921 \mathrm{e}-06$

6.861e-06

$4.744 \mathrm{e}-06$

$3.281 \mathrm{e}-06$

$2.269 \mathrm{e}-06$

$1.569 \mathrm{e}-06$

$1.085 \mathrm{e}-06$

$7.504 \mathrm{e}-07$

$5.189 \mathrm{e}-07$

$3.589 \mathrm{e}-07$

2.482e-07

$1.716 \mathrm{e}-07$

[kg m^-3]
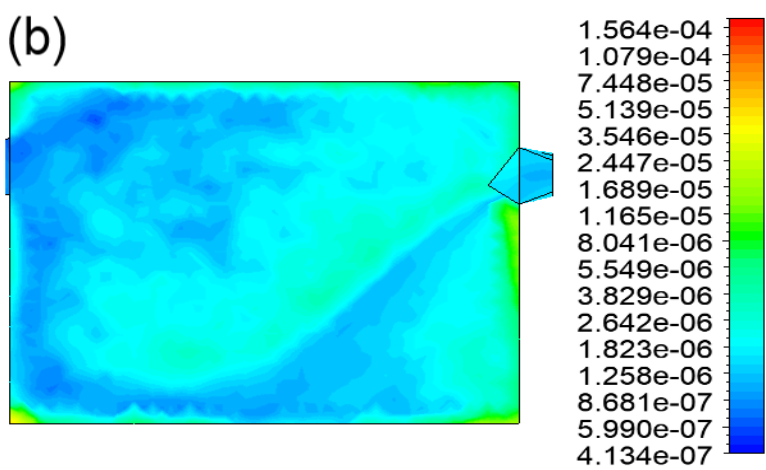

[kg m^-3]
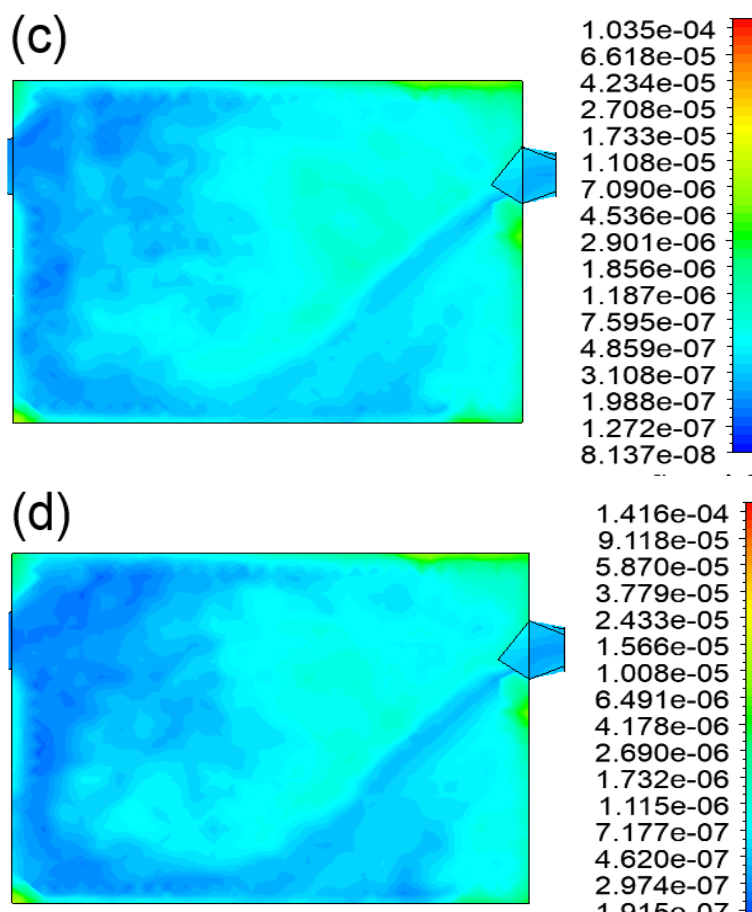

$1416 \mathrm{e}-04$

$9.118 \mathrm{e}-05$

$5.870 \mathrm{e}-05$

$3.779 \mathrm{e}-05$

$2.433 \mathrm{e}-05$

$1.566 \mathrm{e}-05$

1.008e-05

6.491e-06

$4.178 \mathrm{e}-06$

2.690e-06

$1.732 \mathrm{e}-06$

1.115e-06

7.177e-07

4.620e-07

2.974e-07

$1.915 \mathrm{e}-07$

1.233e-07

[kg m $\mathrm{m}^{\wedge}-3$ ]

Fig. 9. Aerosol concentration in chamber 1 at centerline of flow during steady-state in (a) treatment 1, (b), treatment 2, (c) treatment 3, and (d) treatment 4. 
The current study filled this research gap and provided evidentiary support that CFD is a strong tool that can be used to further understand aerosol transmission of infectious pathogens. Specifically, the study sought to validate the performance of CFD at simulating the movement of aerosols within an enclosed space with per head of sow airflow rates used during mild and warm weather in hog barns (MWPS 1983). Small aerosols were used in the experiments and simulations as they are capable of penetrating deep in the respiratory system and are important in aerosol transmission. The CFD simulations tracked the movement of uniform-diameter liquid aerosols in chambers with known airflow rates, aerosol generation rates, and boundary conditions. The results of the CFD simulations were validated with aerosol concentrations measured at one location for the time period required for aerosols to reach a steady-state concentration. The airflow pattern observed in the simulation was also compared to the airflow behaviour seen in smoke tests.

\section{CONCLUSIONS}

The CFD modeling of the airflow pattern and aerosol concentration within the mechanically-ventilated chambers was successful. The CFD simulations replicated the airflow behaviour observed in the smoke test. The CFD simulations performed within the NMSE and FB guidelines for indoor air quality models as the aerosol concentration reached steady-state (i.e., after $400 \mathrm{~s}$ for treatments 1 and 2, and after $120 \mathrm{~s}$ for treatments 3 and 4). At steady-state, the lowest and highest differences occurred in treatments three and four $(2 \%)$, and treatment $1(8 \%)$, respectively, and all the treatment simulations met the NMSE and FB criteria provided by ASTM. However, the simulations were not within the NMSE and FB criteria during the transient stage of the simulation. This paper also indicated the importance of including mesh refinement tests within CFD simulations, as the mesh size can affect the accuracy of the simulated results. The mesh refinement tests indicated that a predominant cell size of $0.05 \mathrm{~m}$ was appropriate in this application.

There were limitations to the current study. More experimental replicates should have been performed per treatment to improve the ability to simulate and validate the transient aerosol concentration. Additionally, because the aerosol concentration measurements were performed at one location in the chamber, the spatial distribution of aerosols determined in the CFD simulations could not be validated in this study. Despite these limitations, the current study was a success. The study showed that CFD is a strong tool that can model the movement of pathogen-laden aerosols. Future studies should include measurements at multiple locations in order to allow for a more comprehensive validation of CFD simulations. Additionally, more replicates per treatment should be performed to allow for better simulation and validation of the transient phase of the simulation. Lastly, CFD simulation and validation of longdistance aerosol transport should be performed as well.

\section{ACKNOWLEDGEMENTS}

We would like to thank Manitoba Pork and Manitoba Rural Adaptation Council (MRAC) for their funding support. We would also like to thank Dr. David Levin and Dr. Kevin Coombs for their technical expertise during the experimental phase of this study as well as Dr. Kevin Coombs for providing the PRRSV utilized in this study.

\section{REFERENCES}

Alexandersen, S., I. Brotherhood and A.I. Donaldson. 2002. Natural aerosol transmission of foot-and-mouth disease virus to pigs: minimal infectious dose for strain O1 Lausanne. Epidemiology and Infection 128: 301-312. https://doi.org/10.1017/S095026880100646X

ANSYS 2013a. ANSYS fluent user's guide, Release 15.0, Canonsburg, PA: ANSYS Inc.

ANSYS 2013b. ANSYS fluent theory guide, Release 15.0, Canonsburg, PA: ANSYS Inc.

ASHRAE. 1987. Standard methods for laboratory airflow measurement. STD 41.2. Atlanta, PA: American Society of Heating, Refrigeration \& Air-Conditioning Engineers.

ASTM. 2008. Standard guide for statistical evaluation of indoor air quality models. D5157-97. West Conshohocken, PA: ASTM International.

Brockmeier, S.L. and K.M. Lager. 2002. Experimental airborne transmission of porcine reproductive and respiratory syndrome virus and Bordetella bronchiseptica. Veterinary Microbiology 89: 267-275. https://doi.org/10.1016/S0378-1135(02)00204-3

Cambra-López, M., A.J.A. Aarnink, Y. Zhao, S. Calvet and A.G. Torres. 2010. Airborne particulate matter from livestock production systems: a review of an air pollution problem. Environmental Pollution 158: 117. https://doi.org/10.1016/j.envpol.2009.07.011

Camfil. 2017. XS Absolute standard capacity HEPA filter. http://www.camfil.us/FileArchive/_30_Product_Sup port_Material_CamTab/Product $\% 20$ Literature/Ā bsol ute $\%$ 20HEPA $\%$ 20and\%20ULPA\%20Filters/Absolut e\%20XS\%20Standard\%20Capacity\%20HEPA\%20Fi lter\%20Product\%20Sheet.pdf. (2017/05/02).

Chen, P., F.T. Tsai, C.K. Lin, C. Yang, C. Chan, C. Young and C. Lee. 2010. Ambient influenza and avian influenza virus during dust storm days and background days. Environmental Health Perspectives 118: 1211-1216. https://doi.org/10.1289/ehp.0901782

Cho, J.G., J. Deen and S.A. Dee. 2007. Influence of isolate pathogenicity on the aerosol transmission of porcine reproductive and respiratory syndrome virus. Canadian Journal of Veterinary Research (71): 23-27.

Colenutt, C., J.L. Gonzales, D.J. Paton, J. Gloster, N. Nelson and C. Sanders. 2016. Aerosol transmission of foot-and-mouth disease virus Asia-1 under 
experimental conditions. Veterinary Microbiology 189: 39-45.

https://doi.org/10.1016/j.vetmic.2016.04.024

Continental Fans. 2012. IRIS damper product specification guide. IRIS-Spec-1102-11. Mississauga, ON: Continental Fan Canada Inc.

De Nevers, N. 2010. Air Pollution Control Engineering, 3rd Edition. Long Grove, Illinois: Waveland Press, Inc.

Dee, S., S. Otake, S. Oliveira and J. Deen. 2009. Evidence of long distance airborne transport of porcine reproductive and respiratory syndrome virus and Mycoplasma hyopneumoniae. Veterinary Research 40(4):39. https://doi.org/10.1051/vetres/2009022

Dee, S., S. Otake and J. Deen. 2010. Use of a production region model to assess the efficacy of various air filtration systems for preventing airborne transmission of porcine reproductive and respiratory syndrome virus and Mycoplasma hyopneumoniae: results from a 2-year study. Virus Research 154: 177-184. https://doi.org/10.1016/j.virusres.2010.07.022

Donaldson, A.I., C.F. Gibson, R. Oliver, C. Hamblin and K.P. Kitching. 1987. Infection of cattle by airborne foot-and-mouth disease virus: minimal doses with $\mathrm{O} 1$ and SAT 2 strains. Research in Veterinary Science 43(3): 339-346. https://doi.org/10.1016/S00345288(18)30804-X

Duguid, J.P. 1946. The size and the duration of air-carriage of respiratory droplets and droplet-nuclei. Journal of Hygiene 44(6):471-479.

https://doi.org/10.1017/S0022172400019288

Gibson, C.F. and A.I. Donaldson. 1986. Exposure of sheep to natural aerosols of foot-and-mouth disease virus. Research in Veterinary Science 41(1): 45-49. https://doi.org/10.1016/S0034-5288(18)30570-8

Gloster, J., H.J. Champion, J.H. Sørensen, T. Mikkelsen, D.B. Ryall, P. Astrup, S. Alexandersen and A.I. Donaldson. 2003. Airborne transmission of foot-andmouth disease virus from Burnside Farm, Heddon-onthe-Wall, Northumberland, during the 2001 epidemic in the United Kingdom. Veterinary Record 152: 525533. https://doi.org/10.1136/vr.152.17.525

Guan, J., Q. Fu, M. Chan and J.L. Spencer. 2013. Aerosol transmission of an avian influenza H9N2 virus with a tropism for the respiratory tract of chickens. Avian Diseases 57: 645-649. https://doi.org/10.1637/10486010913-Reg.1

Guan, J., Q. Fu and S. Sharif. 2015. Replication of an H9N2 avian influenza virus and cytokine gene expression in chickens exposed by aerosol or intranasal routes. Avian Diseases 59: 263-268.

https://doi.org/10.1637/10972-110714-Reg

Jennings. S.G. 1988. The mean free path in air. Journal of Aerosol Science 19(2):159-166.

https://doi.org/10.1016/0021-8502(88)90219-4
Kristensen, C.S., A. Bøtner, H. Takai, J.P. Nielsen and S.E. Jorsal. 2004. Experimental airborne transmission of PRRSV. Veterinary Microbiology 99: 197-202. https://doi.org/10.1016/j.vetmic.2004.01.005

La, A., Q. Zhang, K. Coombs and D. Levin. 2013. Assessment of the performance of electrostatic space charge system (ESCS) at improving barn air quality. In CSBE/SCGAB 2013 Annual Conference, University of Saskatchewan, Saskatoon, SK, 7-10 July 2013.

La, A. 2015. Effectiveness of negative air ionization in reducing airborne porcine reproductive and respiratory syndrome virus (PRRSV) and aerosols. Unpublished M.Sc. thesis. Winnipeg, Manitoba: Biosystems Engineering, University of Manitoba.

Launder, B. E. and D. B. Spalding. 1972. Lectures in Mathematical Models of Turbulence. London, England: Academic Press.

Lee, H.-J., K. Suh, N.-S. Jung, I.-B. Lee, I.-H. Seo, O.-K. Moon and J.-J. Lee. 2014. Prediction of the spread of highly pathogenic avian influenza using a multifactor network: part 2 - comprehensive network analysis with direct/indirect infection route. Biosystems Engineering 118: 115-227. https://doi.org/10.1016/j.biosystemseng.2013.11.009

Li, Y., X. Huang, I. T S Yu, T. W. Wong and H. Qian. 2004. Role of air distribution in SARS transmission during the largest nosocomial outbreak in Hong Kong. Indoor Air 15 (2): 83-95. https://doi.org/10.1111/j.16000668.2004.00317.x

MWPS. 1983. Swine housing and equipment handbook. MWPS-8. Ames, Iowa: Midwest Plan Service.

Mikkelsen, T., S. Alexandersen, P. Astrup, H.J. Champion, A.I. Donaldson, F.N. Dunkerley, J. Gloster, J.H. Sørensen and S. Thykier-Nielsen. 2003. Investigation of airborne foot-and-mouth disease transmission during low-wind conditions in the early phase of the UK 2001 epidemic. Atmospheric Chemistry and Physics 3:2101-2110. https://doi.org/10.5194/acp-32101-2003

Otake, S., S. Dee, C. Corzo, S. Oliveira and J. Deen. 2010. Long distance airborne transport of infectious PRRSV and Mycoplasma hyopneumonaie from a swine population infected with multiple viral variants. Veterinary Microbiology 145: 198-208. https://doi.org/10.1016/j.vetmic.2010.03.028

Pitkin, A., J. Deen and S. Dee. 2009. Use of a production region model to assess the airborne spread of porcine reproductive and respiratory syndrome virus. Veterinary Microbiology 136: 1-7. https://doi.org/10.1016/j.vetmic.2008.10.013

Seo, I.-H., I.-B. Lee, M.-H. Shin, G.-Y. Lee, H.-S. Hwang, S.-W. Hong, J. P. Bitog, J.-I. Yoo, K.-S. Kwon, Y.-H. Kim and T. Bartzanas. 2010. Numerical prediction of fugitive dust dispersion on reclaimed land in Korea. 
Transactions of the ASABE 53(3): 891-901. https://doi.org/10.13031/2013.30072

Seo, I., I.-B. Lee, O.-K. Moon, N.-S. Jung, H.-J. Lee, S.-W. Hong, K.-S. Kwon and J. P. Bitog. 2014. Prediction of the spread of highly pathogenic avian influenza using a multifactor network: part 1 - development and application of computational fluid dynamics simulations of airborne dispersion. Biosystems Engineering 121: 160-176. https://doi.org/10.1016/j.biosystemseng.2014.02.013

Spekreijse, D., A. Bouma, G. Koch and J.A. Stegeman. 2011. Airborne transmission of a highly pathogenic avian influenza virus strain $\mathrm{H} 5 \mathrm{~N} 1$ between groups of chickens quantified in an experimental setting. Veterinary Microbiology 152: 88-95. https://doi.org/10.1016/j.vetmic.2011.04.024

Spekreijse, D., A. Bouma, G. Koch and A. Stegeman. 2013. Quantification of dust-borne transmission of highly pathogenic avian influenza virus between chickens. Influenza and Other Respiratory Viruses 7 (2): 132138 . https://doi.org/10.1111/j.17502659.2012.00362.x

Ssematimba, A., T.J. Hagenaars and M.C.M. de Jong. 2012. Modelling the wind-borne spread of highly pathogenic avian influenza virus between farms. PLoS ONE 7(2).

https://doi.org/10.1371/journal.pone.0031114

Topas. 2010. Laser aerosol particle size spectrometer instruction manual. LAP 322. Dresden, Germany: Technologie-orientierte Partikel-, Analysen- und Sensortechnik.

Torremorrell, M., C. Pijoan, K. Janni, R. Walker and H.S. Joo. 1997. Airborne transmission of Actinobacillus pleuropneumoniae and porcine reproductive and respiratory syndrome virus in nursery pigs. American Journal of Veterinary Research 58(8): 828-832.

Tsukamoto, K., T. Imada, N. Tanimura, M. Okamatsu, M. Mase, T. Mizuhara, D. Swayne and S. Yamaguchi. 2007. Impact of different husbandry conditions on contact and airborne transmission of H5N1 highly pathogenic avian influenza virus to chickens. Avian Diseases 51 (1): 129-132.

https://doi.org/10.1637/0005-

2086(2007)051[0129:IODHCO]2.0.CO;2
Wong, T.W., C.K. Lee, W. Tam, J.T.F. Lau, T.S. Yu, S.F. Lui, P.K.S. Chan, Y. Li, J.S. Bresee, J.J.Y. Sung and U.D. Parashar. 2004. Cluster of SARS among medical students exposed to single patient, Hong Kong. Emerging Infectious Diseases 10 (2): 269-276. https://doi.org/10.3201/eid1002.030452

Wong, B.C.K., N. Lee, Y. Li, P.K.S. Chan, H. Qiu, Z. Luo, R.W.M. Lai, K.L.K. Ngai, D.S.C. Hui, K.W. Choi and I.T.S. Yu. 2010. Possible role of aerosol transmission in a hospital outbreak of influenza. Clinical Infectious Diseases 51 (10): 1176-1183.

https://doi.org/10.1086/656743

Yang, S, G.W. M. Lee, C.-M. Chen, C.-C. Wu and K.-P. $\mathrm{Yu}$. 2007. The size and concentration of droplets generated by coughing in human subjects. Journal of Aerosol Medicine 20(4): 484-494. https://doi.org/10.1089/jam.2007.0610

Yao, M., X. Zhang, J. Gao, T. Chai, Z. Miao, W. Ma, M. Qin, Q. Li, X. Li, J. Liu and H. Zhang. 2011. The occurance and transmission characteristics of airborne H9N2 avian influenza virus. Berliner und Münchener Tierärztliche Wochenschrift 124: 136-141.

Yu, I.T.S., Y. Li, T.W. Wong, W. Tam, A.T. Chan, J.H. W. Lee, D.Y.C. Leung and T. Ho. 2004. Evidence of airborne transmission of the severe acute respiratory syndrome virus. The New England Journal of Medicine 350 (17): 1731-1739. https://doi.org/10.1056/NEJMoa032867

Yu, I.T.S., T.W. Wong, Y.L. Chiu, N. Lee and Y. Li. 2005. Temporal-spatial analysis of severe acute respiratory syndrome among hospital inpatients. Clinical Infectious Diseases 40 (9): 1237-1243. https://doi.org/10.1086/428735

Zhao, Y., A.J.A. Aarnink, M.C.M. De Jong and P.W.G.G. Koerkamp. 2014. Airborne microorganisms from livestock production systems and their relation to dust. Critical Reviews in Environmental Science 44:10711128. https://doi.org/10.1080/10643389.2012.746064 